\title{
AFINAL, ISSO É ANTROPOLOGIA? UMA AUTOETNOGRAFIA DE EXPERIÊNCIAS (ENTRE O MERCADO E O PÚBLICO) EM ANTROPOLOGIA AUDIOVISUAL APLICADA
}

\author{
Luisa Godoy Pitanga ${ }^{1}$
}

\begin{abstract}
Observando os Estudos de Impacto Ambiental desses projetos, os chamados EIA/RIMAS, é possível compará-los à Carta de Pero Vaz de Caminha. Os EIA/RIMAS, ao invés de analisarem os reais impactos socioculturais e ambientais que esses projetos causarão ao meio ambiente e às populações locais, são utilizados como instrumentos ideológicos de promoção da recolonização e é exatamente por isso que prefiro chamá-los de projetos de expropriamento. A situação é muito grave. Será preciso de nossa parte um grande esforço de interpretação dessas novas versões da Carta de Pero Vaz de Caminha, os chamados EIA/RIMAS, até porque esses estudos são descritos em linguagens bem diferentes das nossas, com o propósito deliberado de nos excluir dos processos de discussão e de tomada das decisões, quando não buscam nos iludir com falsas promessas de melhorias de vida. (Bispo, 2015: $71-72)$
\end{abstract}

Em Colonização, Quilombos: modos e significações, Antonio Bispo, intelectual contra-colonial quilombola, morador do quilombo Saco/Curtume em São João do Piauí (PI), chama a atenção para a colonialidade incutida na narrativa dos Estudos de Impacto Ambiental (EIA-RIMA) ${ }^{2}$ produzidos por empresas de consultoria para licenciamento ambiental de grandes empreendimentos, comparando-os às cartas de missões coloniais e suas descrições do ambiente e do outro.

A consultoria para licenciamento ambiental de grandes empreendimentos é uma das inserções profissionais de cientistas sociais que surge de processos de ambientalização ${ }^{3}$ em empresas, no Estado e na sociedade civil (Leite Lopes, 2006), sendo

\footnotetext{
${ }^{1}$ Universidade Federal do Rio Grande do Sul, Brasil. E-mail: luisapitanga@gmail.com ORCID id: https://orcid.org/0000-0003-3274-3717

${ }^{2}$ A Resolução n. 001, de 23 de janeiro de 1986, do Conselho Nacional do Meio Ambiente (CONAMA) regulamentou a avaliação de impactos ambientais no Brasil ao estabelecer definições, responsabilidades, critérios e diretrizes para seu uso e elaboração e instituiu a obrigatoriedade de apresentar estudos para o licenciamento de grande número de empreendimentos. Os instrumentos para realizar a avaliação de impacto são: o EIA (Estudo de Impacto Ambiental) e o RIMA (Relatórios de Impacto sobre o Meio Ambiente). Neste contexto as firmas de consultoria ambiental se lançaram rapidamente no mercado e houve a proliferação no país de uma verdadeira "indústria" de elaboração de EIA-RIMAs. (Rovere, 1995:141).

${ }^{3}$ Entende-se por "ambientalização", o neologismo cunhado para indicar "um processo histórico de construção de novos fenômenos associado a um processo de interiorização pelas pessoas e pelos grupos sociais (...) das diferentes facetas da questão pública do meio ambiente" (Leite Lopes, 2004:26). A noção de "ambientalização" tem apoiado a "caracterização da historicidade da questão ambiental" e "sua pertinência teórica ganha porém, força particular na possibilidade de caracterizar processos de
} 
uma forma de pesquisa aplicada que se desenvolve na intersecção entre poder público (órgão ambiental que fiscaliza, normatiza e licencia, por exemplo, o IBAMA ou órgão interveniente no caso de comunidades tradicionais, como INCRA e FUNAI), empresas privadas ou estatais de energia (responsáveis pelo empreendimento e financiadora dos estudos de impacto e projetos) e empresas de consultoria ${ }^{4}$ (responsáveis pelos estudos e programas de mitigação e compensação).

O mercado de trabalho em consultoria ambiental se estruturou e se mantém economicamente graças à exigência legal do licenciamento ambiental, que obriga empresas interessadas a implantar grandes empreendimentos voltados para extração de petróleo e gás, produção de hidroeletricidade, instalação de portos, subestações e linhas de transmissão, extração de minérios terrestres diversos, entre outras atividades consideradas como potencialmente poluidoras, a financiarem a elaboração de estudos de impacto ambiental e de projetos socioambientais com medidas de mitigação e compensação de impactos.

O sistema de classificação dos estudos de impacto ambiental divide o ambiente em meios: meio físico, meio biótico e meio socioeconômico. Cada meio mobiliza diferentes expertises/ especialidades profissionais para elaboração dos estudos:

(i) cientistas da natureza (biólogos, geólogos, geógrafos, oceanógrafos, etc.), responsáveis pelos estudos sobre as condições físicas e biológicas dos ambientes de localização dos empreendimentos e responsáveis pelas avaliações de impacto ambiental e análises de risco; (ii) economistas e cientistas sociais (geógrafos, sociólogos e antropólogos) voltados à produção de conhecimento sobre as populações localizadas próximas aos empreendimentos e os efeitos aos quais estarão sujeitas; (iii) engenheiros para elaboração da parte dos Planos Básicos relativos aos projetos de engenharia e ao planejamento das obras de construção dos empreendimentos (Bronz, 2011 : 54).

O presente artigo é fruto da dissertação de mestrado Ambientalização, audiovisual e desenvolvimento: percursos etnobiográficos (2015), uma autoetnografia em que abordei experiências pessoais/profissionais vivenciadas na condição de consultora ambiental de

ambientalização específicos a determinados lugares, contextos e momentos históricos” (Acselrad, 2010: 34).

${ }^{4}$ Segundo Bronz, "essas firmas de consultoria são contratadas pelas empresas para realizar o Estudo de Impacto Ambiental através da subcontratação de consultores - técnicos e cientistas (especialistas) - com diferente formação, capazes de suprir as demandas dos conteúdos do EIA, fixados pelo órgão ambiental responsável pela concessão da licença através da emissão do Termo de Referência” (BRONZ, 2011: 54). 
meio socioeconômico, documentarista e educadora audiovisual popular em processos de licenciamento ambiental federal de grandes empreendimentos energéticos.

Abordar tais vivencias no mestrado não era a intenção inicial. Na época da qualificação, entreguei um texto à banca com uma introdução onde abordava minha trajetória apenas como forma de contextualizar o interesse no tema original do meu projeto, representações audiovisuais da Amazônia. Uma das professoras da banca disse que eu deveria redirecionar o projeto e tomar por objeto de análise essas experiências pessoais e profissionais como pesquisadora, pois havia interesse acadêmico em conhecer mais das inserções de cientistas sociais fora da universidade. Para isso deveria fazer uso de um tipo de etnografia ainda completamente desconhecido por mim, a autoetnografia. $\mathrm{Na}$ época da escrita da dissertação, 2014, havia pouca bibliografia sobre o assunto disponível em português e na disciplina de Metodologia que cursei a autoetnografia não foi mencionada como possibilidade.

Abordar as próprias vivências não foi simples, gerou muitos rodeios, tergiversações e planos de fuga. Falar de si já é tema espinhoso, sendo mais ainda quando se trata da complexa teia de relações sociais que atravessa os projetos industriais de desenvolvimento e envolve grandes empresas, poder público e grupos atingidos por empreendimentos. Além dos desafios epistemológicos relacionados a etnografar as próprias experiências, antes da qualificação eu não vislumbrava esse conjunto de experiências como um possível campo de pesquisa.

A minha negação talvez se devesse ao que João Pacheco de Oliveira (2013) apontou como "um certo mal-estar" por parte do universo acadêmico em relação aos estudos classificados como "aplicados". A denominação "coloca os seus resultados automaticamente sob suspeita de serem menos permanentes e fundamentados do que outros não rotulados deste modo". Sua hipótese é que este incômodo resulta de uma espécie de desencontro cultural "entre as práticas concretas de investigação e as auto representações da disciplina, entre o cotidiano da pesquisa e o discurso normativo que dirige a formação de novos antropólogos" (Pacheco de Oliveira, 2013 :49).

O "mal-estar" da academia em relação aos estudos aplicados de certa forma me atingia, pois, o trabalho de campo que eu idealizava e legitimava como antropológico era aquele em que passamos meses seguidos em uma determinada localidade convivendo com o grupo estudado e em que o pesquisador se apresenta como antropólogo vinculado a alguma instituição acadêmica. A prática do consultor que trabalha no licenciamento de 
grandes empreendimentos se desdobra no arranjo entre: condições de pesquisa (técnicas, éticas e econômicas); interpretação e cumprimento de exigências da administração pública e relações de clientela das empresas interessadas em licenciar seus projetos com empresas de consultoria que contratam profisssionais de diferentes formações, entre elas cientistas sociais.

A antropóloga Deborah Bronz (2011) que, na condição de consultora, pôde ter acesso a esse universo social, faz uma pertinente reflexão que alude ao papel dos cientistas sociais no licenciamento ambiental, um procedimento administrativo imerso em contradições e relações complexas entre Sociedade-Empresa-Estado:

\begin{abstract}
Se os cientistas sociais não se dedicarem a este trabalho, quem o fará? Se, por toda atitude crítica implicada em nossa formação, os cientistas sociais não podem 'moralmente' assumir esse lugar de trabalho, que formações profissionais poderiam dar conta destes contextos relacionados a processos de grande mudança social, com graves implicações sobre os modos de vida das populações e comunidade locais? E, ainda, se a regulação ambiental brasileira 'abre' caminho para que se instaurem procedimentos de avaliação sobre os efeitos sociais dos grandes empreendimentos, que envolvam o trabalho de cientistas sociais e a 'participação' de associações civis, por que não ocupálos? Estas perguntas, que até hoje ecoam em minhas reflexões, de algum modo dirimiram minhas inquietudes, me acalmaram e até me estimularam a seguir com o trabalho de consultoria (Bronz, 2011: 57).
\end{abstract}

Afora as contradições inerentes a uma narração do self, busquei uma ideia que me ajudasse a tecer essas experiências sem totalizá-las, que tivesse fluidez e caracterizasse os caminhos trilhados por um indivíduo. Inspirada pelas "enunciações pedestres" de Michel de Certeau (2007), que aproximam o caminhar do transeunte pela cidade ao ato de enunciar do falante, me propus a estabelecer o que chamei de percursos etnobiográficos ou auto etnografia andarilha. Para Certeau, o ato de caminhar está para o sistema urbano como a enunciação está para a língua. Assim, cada percurso seria um relato. O caminhar seria processual, um escape às tentativas de fixação do sistema espacial. O mapa demarca e fixa, já o "percurso" é um ato de enunciação que fornece uma série de caminhos sobre os modos de usar o sistema. Para Certeau, esses modos de fazer são repletos de "táticas", que seriam aquelas pequenas transgressões e astúcias que os pedestres/consumidores desenvolvem na relação com a cidade e que passam ao largo do sistema. (Certeau, 2007)

Os relatos/ percursos, as caminhadas e as táticas me pareceram analogias afins ao que seria o trabalho do consultor ambiental, também constituído pela dimensão da narrativa, da viagem e da ação por dentro da estrutura. Dentre as táticas utilizadas nos 
meus percursos na consultoria, estava o uso de outra linguagem e de outros meios nos projetos e estudos: a linguagem audiovisual, na forma de documentários, e o uso da câmera, como instrumento de observação e de relação na pesquisa e em processos participativos de educação ambiental, que abordarei mais adiante.

\title{
Etnografia, biografia e self: definindo lugares híbridos de enunciação
}

No livro Autoetnografias - conceitos alternativos em construção (2005), a antropóloga Daniela Versiani faz uma leitura crítica da coletânea Auto/ Etnography: Rewriting the self and the social (1997), organizada pela antropóloga Deborah ReedDanahay, em que o termo autoetnografia foi proposto a 8 antropólogos para construir sentidos para o termo. Versiani identifica pelo menos três perspectivas na adoção do termo autoetnografia pelos autores em questão:

\begin{abstract}
Native anthropology ou etnografias produzidas por membros do grupo estudado que receberam treinamento formal em antropologia e que retornam ao seu grupo cultural de origem para escrever uma etnografia (1); ethnic autobiographies ou narrativas, testemunhos, relatos de vida ou autobiografias escritas por autores membros de grupo étnico escolhidos como tema de investigação (2); autobiographical ethnography ou escritos auto-reflexivos de antropólogos cuja experiência pessoal e profissional é inserida e analisada na própria escrita etnográfica, especialmente marcada por preocupações metodológicas e epistemológicas, como a reflexão sobre o processo de construção de conhecimento antropológico (3). ( Versiani, 2005: 211 )
\end{abstract}

Para Reed-Danahay a autoetnografia se caracteriza por uma série de ambiguidades, inversões, sobreposições que modificam a perspectiva etnográfica:

\begin{abstract}
a presença de elementos narrativos que oferecem uma ligação entre particular e coletivo ao descrever um modo de vida e ao mesmo tempo nos falar sobre acontecimentos de uma vida em particular; coincidência entre autor da narrativa e objeto narrado, seu próprio self; sobreposição de gêneros (autobiografia e etnografia) e inversão de papéis: enquanto em sua concepção tradicional do etnógrafo traduz uma 'cultura estrangeira' para uma audiência nativa, o autoetnógrafo supostamente traduziria uma cultura nativa para uma audiência estrangeira (Reed-Danahay, 1997 apud Versiani, 2005 :150).
\end{abstract}

Tais especificidades colocam o autor de autoetnografia na posição híbrida de insider/outsider (nativo/estrangeiro), localizado em uma "zona de fronteira" ou "entre duas culturas", portador de uma identidade bicultural (Idem, p. 149). O sujeito autoetnográfico acumula e soma "múltiplas pertenças e experiências passadas, 
decorrentes de sua singular trajetória de identificações com diferentes grupos socioculturais, memórias e tradições" (Versiani, 2005: 212) e tem como pressupostos a complexidade, a mobilidade e a singularidade do indivíduo.

$\mathrm{Na}$ bibliografia sobre novas inserções profissionais de antropólogas há uma diversidade de relatos que dialoga com a posição ambígua de insider/outsider daqueles que atuam fora do esquema acadêmico. No artigo $O$ estrangeiro em "campo": atritos e deslocamentos no trabalho antropológico (2003), Patrice Schuch analisa sua experiência como antropóloga em duas esferas distintas de produção de conhecimento: na academia e numa instituição de intervenção social, a FEBEM/RS (Fundação Estadual do Bem-Estar do Menor do Rio Grande do Sul). A antropóloga Alinne Bonetti tematiza dois lugares de enunciação distintos que conformam uma hibridez ao relatar no artigo $A O N G$ e a antropóloga - Da experiência etnográfica à experiência profissional (2004) sua experiência de inserção profissional em uma ONG feminista que pesquisava. Dentre os relatos reflexivos de antropólogos acerca de suas experiências extra-muros o de Barbara Soares no artigo A Antropologia no executivo: limites e perspectivas (2005) que aborda o período em que ocupou um cargo executivo no governo do estado do Rio de Janeiro como responsável pela implantação do Programa Estadual de Segurança da Mulher é dos mais contundentes.

\footnotetext{
O fato de eu desempenhar, naquelas situações, o papel da autoridade, era ainda mais revelador, pois como personagem da cena que observava, eu tinha o privilégio de conhecer pela própria experiência, a gramática utilizada por certos grupos, na relação com o que eles consideravam ser uma representante do poder (...) Mas, sempre que me entretinha observando formações conceituais, estruturas de plausibilidade, feixes de significados, ambiguidades e tensões constitutivas dos discursos e das práticas de meus interlocutores, lembrava-me subitamente de meus compromissos profissionais como subsecretária adjunta: era preciso dar respostas precisas às demandas, solucionar as disputas, negar ou aceitar as propostas, definir caminhos, avaliar os procedimentos e oferecer alternativas aos problemas enunciados. (Soares, 2005: 59).
}

Tal ambiguidade ou condição híbrida também passa por um jogo de luz e sombra entre o que fica oculto, incomunicável e o que se pode mostrar e dizer. E essa observação escamoteada pode nos oferecer uma visão privilegiada das relações, dos conflitos, das estratégias que envolvem aqueles atores com os quais estamos interagindo.

As relações de dominação na produção de conhecimento vivenciadas no campo do licenciamento, me levam a discorrer sobre a própria constituição desta (auto)etnografia. Da perspectiva antropológica acadêmica, a etnografia se dá a partir da "disposição em 
viver uma experiência pessoal junto a um grupo humano com o fim de transformar essa experiência pessoal em tema de pesquisa que assume a forma de um texto etnográfico" (Goldman,2006 :156). No caso de minhas práticas de consultoria, as disposições em jogo eram semelhantes no que tange à ideia de transformar uma experiência em tema de pesquisa, que se torna um texto. Mas se tratava de práticas desenvolvidas em situação de dominação social, regidas pelo tempo do mercado e delimitadas pelas exigências do Estado. Como poderia etnografá-las se eu fosse outsider? Bronz usa o termo participantinsider (Mosse, 2005 apud Bronz, 2011:63) para qualificar a etnografia em que "o investigador não apenas está comprometido com aqueles com os quais se relaciona, como se torna um agente das ações e processos que analisa (...)isto é, um observador posicionado no interior da rede de relações e conexões que constituem o projeto" (Idem, pp. 63 -64), já que não seria possível observar as práticas empresariais no licenciamento sem estar dentro daqueles processos como prestador de serviços.

\section{Afinal, isso é antropologia? A pesquisa de campo na consultoria ambiental}

Os percursos na consultoria me trouxeram novos enfrentamentos como o aprendizado de um novo idioma composto por siglas e termos do qual deveria me apropriar rapidamente para trabalhar no licenciamento, as distorções decorrentes das relações de clientela com grandes empresas e a hierarquização entre os diferentes saberes técnicos-científicos, que se manifesta na hegemonia das Ciências Exatas e Biológicas sobre as Ciências Sociais ${ }^{5}$ na área ambiental e, implicitamente presente nos valores de orçamentos, com investimentos maiores nas pesquisas dos meios físico e biótico, em detrimento do meio socioeconômico:

Também é regra tácita que os orçamentos destinados à realização de coletas e experimentações, bem como às modelagens de risco, que compõem a descrição dos fenômenos naturais, sejam muito maiores do que as despesas dos consultores da parte socioeconômica, com suas equipes reduzidas e rápidas incursões ao local também chamado de ‘campo'. Não é comum a produção de

\footnotetext{
${ }^{5}$ No Brasil, alguns desafios se impõem aos cientistas sociais para observação e análise dos temas ambientais. Temos como obstáculos a histórica apropriação acadêmica, política e social do campo ambiental pelos cientistas naturais em detrimento dos cientistas sociais (Drummond, 2006 apud Carneiro et al., 2008). Afora isso a falta de conhecimento sobre os fatores naturais, bióticos e físicos e um interesse tardio em questões ambientais por parte dos cientistas sociais. Todos esses fatores repercutem na "ausência do recurso ao conhecimento sociológico pelos tomadores de decisão no que diz respeito à política para conservação da biodiversidade" (Carneiro et al., 2008: 8).
} 
dados primários com representatividade estatística na realização dos estudos socioeconômicos. O máximo que se consegue é realizar uma coleta breve de informações por meio da observação direta e realizar entrevistas semiestruturadas para subsidiar uma análise qualitativa pouco aprofundada (Bronz, 2011: 104).

A descrição de Bronz é certeira, especialmente na sua descrição do que seria o "campo" dos consultores do "meio socioeconômico", mas é preciso relacionar as desigualdades presentes no licenciamento ambiental a um contexto mais amplo no qual as ciências humanas e sociais historicamente ocupam um lugar "menor" em relação aos outros campos de conhecimento também no meio acadêmico.

O campo é o lugar de encontro entre consultor e moradores e trabalhadores de localidades que fazem parte da área de influência do empreendimento, que podem ser vilas e povoados rurais, periurbanos ou urbanos. Mesmo em condições precárias de pesquisa, ou seja, com pouco tempo e de forma imprevista, esse encontro em campo é visto como uma oportunidade única. A incerteza do retorno é umas das poucas certezas do consultor. Nada garante que será o mesmo consultor a retornar, que haverá continuidade no projeto porque basicamente esse retorno depende de contratos entre empresas, de decisões de investimento do empreendedor e dos procedimentos de licenciamento que estão alheios à vontade do profissional. Os encontros são de diferentes tipos. Há aqueles previamente marcados e aqueles de surpresa, pois não se tem como contatar ou identificar as pessoas antes. O trabalho do consultor só existe quando ele viabiliza esses encontros, que muitas vezes ocorrem de forma improvisada, a depender do risco e do acaso. Em muitos casos há dificuldade de conseguir contatos prévios devido à infraestrutura das localidades que não tem telefone ou informações disponíveis na internet. No caso de comunidades quilombolas e indígenas, há mediação dos órgãos intervenientes (INCRA ou FUNAI), que contatam as lideranças comunitárias e agendam a reunião informativa, uma forma de consulta prévia com presença das equipes de consultoria, do empreendimento e do poder público antes de iniciar a pesquisa de campo para os estudos ambientais.

Mesmo com alguma previsão e preparação, dificilmente se sabe o que encontrará no campo. Uma das habilidades exigidas aos consultores é o planejamento de viagens. Pensar a organização da logística de transporte e hospedagem de acordo com o orçamento disponível; estudar mapas para elaborar o trajeto de campo que podem incluir translados fluviais, terrestres e aéreos; calcular a duração do campo a partir da extensão, quantidade e infraestrutura de circulação (estradas, rios) dos municípios a serem visitados. A preparação para o campo também é composta por atividades de pesquisa como: 
levantamento de dados secundários pela internet sobre as localidades da área de influência; sistematização de materiais como questionários, roteiros de perguntas, fichas; definição de instrumentos de pesquisa.

Diferente do trabalho de campo do antropólogo, o campo do consultor é panorâmico, superficial, corrido, mas não deixa de ser uma experiência intensa e aplicada de pesquisa social, não deixa de ser um exercício de descentramento pessoal e profissional. O "campo" do pesquisador de socioeconomia é delimitado pela "área de influência", que, por sua vez, é delimitada pelos potenciais "impactos diretos" gerados pelo empreendimento. No caso de uma hidrelétrica, por exemplo, a área de influência é definida pela área a ser alagada pelo reservatório e o local em que se situará a barragem. No que se refere às comunidades tradicionais os critérios são de distância do futuro empreendimento do território das mesmas.

Para atuar como consultor no licenciamento ambiental, o profissional deve estar inscrito no Cadastro Técnico Federal de Atividades e Instrumentos de Defesa Ambiental CTF/AIDA do IBAMA. O cadastro tem como finalidade identificar a pessoa física ou jurídica que presta consultoria ambiental. No ano de 2013, o IBAMA lançou Instrução Normativa (IN número 10, de 27 de maio de 2013) que regulamenta as atividades dos consultores no licenciamento. No caso dos cientistas sociais, não há qualquer distinção entre o que podem fazer sociólogos, antropólogos e cientistas políticos. As atividades previstas são: "realizar estudos e pesquisas sociais, econômicas e políticas; participar da gestão territorial e socioambiental; elaborar documentos técnico científicos" (IBAMA, 2013). Na consultoria temos desde estudos voltados para especificidades das questões indígenas e quilombolas e os que lidam com uma diversidade de populações impactadas (urbanas, rurais, ribeirinhas, pesqueiras). Com exceção dos estudos de "Componente Indígena", não há exigência clara do saber/fazer específico em antropologia nas normativas do órgão ambiental para o licenciamento federal, apesar desse saber/fazer estar contido implicitamente em práticas e categorias utilizadas pelos consultores para realizar seus estudos socioeconômicos.

O que o fazer antropológico acadêmico tem em comum e em que se difere de minha experiência pessoal de pesquisa social fora da universidade? Aliás, podemos chamar este fazer de antropologia? Ou seria genericamente pesquisa social aplicada? O que há de antropológico nessas práticas? Sempre paira a dúvida se minhas experiências em pesquisa aplicada devem ou não ser enquadradas no fazer antropológico. 
Os fundamentos que estruturam o exercício de pesquisa do consultor são termos de referência, metodologias e instrumentos de pesquisa (participativas ou não), logística, prazos e orçamento/financiamento. Os termos de referência são documentos emitidos pelo IBAMA (no caso do licenciamento federal), que orientam as questões que os estudos devem abordar e responder para cada meio específico. Os termos de referência ainda estabelecem parâmetros, indicam referências teóricas e metodológicas. O cumprimento dos mesmos é um dos objetivos do consultor. Entre realizar o estudo e cumprir a norma existe um exercício de interpretação e de adaptação dos termos de referência que é feito principalmente pela equipe de consultores.

O exercício de interpretação pode ser resumido em "entender o que quer o órgão ambiental" ou "responder ao órgão ambiental". O exercício de adaptação para prática é a realização da pesquisa compatibilizando prazo, logística, orçamento e equipe. Os dados obtidos são "consolidados" em relatórios técnicos. Esses relatórios técnicos são transformados em apresentações sintéticas e estudos resumidos para serem debatidos em reuniões públicas. Entendo que esses exercícios de interpretação e adaptação exigidos ao consultor para realizar a pesquisa o colocam em um lugar de agência diante da norma.

Não existe "final de expediente" quando estamos em campo. O diagnóstico não termina nunca era uma frase que sempre usávamos para nos referir àquelas pequenas surpresas que aconteciam fora dos espaços oficiais de trabalho. A pesquisa para o diagnóstico socioeconômicos não se dá apenas naquelas situações em que estamos oficialmente trabalhando, mas também nos intervalos, nas cenas banais, nas conversas informais durante as refeições, nos momentos de folga, no extraoficial, naquilo que os outros acham que precisamos saber e vem nos contar espontaneamente. A isso eu chamaria de um eterno estado de vigília etnográfica. Definitivamente não se faz antropologia (aplicada ou acadêmica) apenas no horário comercial. Temos que estar disponíveis e abertos ao acaso. E nem sempre estaremos com a câmera ligada, inclusive por vezes é melhor que esteja desligada ou fora de vista. Na consultoria vivemos um tipo de imersão distinta daquela do trabalho de campo da antropologia acadêmica, mas há uma inevitável imersão, que sim é mais superficial, porque mais rápida.

Se fizermos uma analogia com o ato de mergulhar, o trabalho de campo antropológico em contexto acadêmico seria um mergulho em águas profundas, no qual temos que ter fôlego para alcançar o fundo, já o da pesquisa aplicada na consultoria um mergulho em águas rasas com cuidado para não darmos cabeçadas na areia. A diferença 
é que a natureza do trabalho e a forma como ele é espacializado nos demanda um olhar que chamaria de panorâmico. Fazemos um travelling da área de influência na tentativa de observar situações, lugares e atividades e conversar com o máximo de pessoas possíveis naquele curto espaço de tempo. Temos que dar conta daquele território, mas não podemos visitar cada casa, cada família numa abordagem censitária. Fazemos uma "amostragem" com base em mapas que nos delimitam a área de influência e a localização do empreendimento, além de indicações de com quem devemos conversar por parte daqueles sujeitos locais com quem travamos relações.

\section{Antropologia audiovisual aplicada como meio de participação/ envolvimento público}

O léxico do licenciamento ambiental parece "incompreensível àqueles que não frequentam os espaços onde eles são enunciados" e é entendido "por um círculo limitado de pessoas, em que se incluem: gestores, legisladores, empresários, consultores, especialistas, alguns acadêmicos e ambientalistas" (Bronz, 2011: 31 ). Diante de tal constatação, Bronz pergunta se "não seria esta uma maneira de demarcar uma distinção entre os que estariam ou não aptos a frequentar os circuitos dos debates e de decisão sobre os grandes empreendimentos?" (Idem: 32). Certamente que sim, se vislumbrarmos “o licenciamento ambiental como um campo assimetricamente estruturado, em que comunidades atingidas encontram-se em condições desiguais de defesa de seus direitos" (Zhouri, 2011 apud Mazurec, $2012: 14$ ).

Nesse campo, um dos capitais prevalecentes é o "capital técnico, representado pelo domínio da linguagem técnico-científica, bem como pelo conhecimento dos procedimentos jurídicos e institucionais que compõem o licenciamento" (Teixeira, 2011 apud Mazurec, 2012:128). No plano normativo, o Relatório de Impacto AmbientalRIMA é o recurso previsto pelo IBAMA para garantir acesso das "comunidades interessadas" às "informações técnicas geradas no Estudo de Impacto Ambiental (EIA)". O RIMA deve ser elaborado numa "linguagem apropriada ao entendimento do público". O que o IBAMA define como linguagem apropriada é bastante genérico como podemos observar no texto a seguir: 
A linguagem utilizada neste documento deve conter características e simbologias adequadas ao entendimento das comunidades interessadas, devendo ainda conter, como instrumento didático auxiliar, ilustrações tais como mapas, quadros, gráficos e demais técnicas de comunicação visual, expondo de modo simples e claro as consequências ambientais do projeto e suas alternativas, comparando as vantagens e desvantagens de cada uma delas. (Portaria Interministerial $\mathrm{N}^{\mathrm{o}} 419$, de 26 de outubro de 2011)

Diferente da maioria dos consultores de socioeconomia, tive a possibilidade de trabalhar no licenciamento com pesquisas que envolviam o uso do recurso audiovisual e de, posteriormente, me tornar "educadora audiovisual", auxiliando pessoas a experimentarem produzir documentários a partir de processos participativos. Essa incompreensão quanto ao papel do pesquisador que faz uso das ferramentas audiovisuais nos processos de investigação também podia ser sentida no mercado de consultoria ambiental para licenciamento de grandes empreendimentos. $\mathrm{O}$ entendimento do audiovisual simplesmente como registro ou de seu aprendizado como apropriação apenas das "técnicas de filmagem" era mais recorrente nas relações com empreendedores, empresas de consultoria e menos entre os analistas dos órgãos ambientais. Por outro lado, também havia quem apostasse naquela inovação denominada "pesquisa videodocumentada". Tal abertura resultou em uma expressiva coletânea de documentários realizada entre 2002 e 2010 no âmbito do licenciamento ambiental federal.

$\mathrm{Na}$ empresa de consultoria da qual fui sócia a equipe era dividida entre os cineastas/cineclubistas e os pesquisadores/cientistas sociais, além do designer gráfico e da administradora. O tipo de serviço que prestávamos era considerado sui generis no mercado de consultoria, pois desenvolvemos uma metodologia própria que envolvia pesquisa social com forte inspiração antropológica e audiovisual, numa junção entre tecnologia digital e linguagem de documentário.

Havia uma pergunta que orientava nossas ações: de que modo tratar conflitos socioambientais extremamente complexos decorrentes de impactos industriais e abordar as mudanças acarretadas pelos grandes empreendimentos na vida das pessoas por meio de imagens e sons?

Os projetos em que trabalhávamos inicialmente envolviam a realização de pesquisas de campo e filmagem de documentários com equipe profissional e posteriormente a realização de oficinas de produção de documentários como parte de diagnósticos participativos junto a moradores de municípios presentes na área de influência do grande empreendimento em questão, além da produção dos relatórios 
técnicos em linguagem escrita. Essas duas formas de pesquisa apresentavam dois tipos de resultado audiovisual:

- Vídeos documentários produzidos por uma equipe formada por cientistas sociais, cineastas e fotógrafos que, em campo, como pesquisadores, realizava entrevistas com indivíduos pertencentes aos grupos sociais "mais vulneráveis" atingidos pelo empreendimento, com filmagem de paisagens naturais, de condições de moradia, de situações de trabalho (pesca, agricultura, extrativismo, comercio etc.), de manifestações culturais e de atividades de lazer, além de entrevistas com atores institucionais, como prefeitos, vereadores, agentes de saúde, lideranças de entidades representativas.

- Vídeos documentários produzidos no contexto de oficina/ diagnóstico participativo por meio de relação de coprodução entre a equipe de consultores e os participantes da oficina: moradores de municípios considerados impactados pelo empreendimento, indivíduos com os mais diversos perfis e vinculações sociais, mas principalmente estudantes e professores da rede pública.

Os vídeos que produzíamos no licenciamento eram anexados aos estudos e relatórios de atividades de projetos de educação ambiental a fim de sensibilizar a equipe do empreendedor para as questões locais, pela voz, corpo, gesto e ação daqueles que viriam a ser impactados pelo seu projeto, além de subsidiar a avaliação do órgão ambiental licenciador. O audiovisual ajudaria os técnicos do órgão ambiental a entenderem melhor a organização social, o desenvolvimento das atividades econômicas, os conflitos ambientais e políticos existentes e poderia transmitir opiniões, sugestões, expectativas, críticas, denúncias, dúvidas dos potenciais atingidos quanto aos futuros empreendimentos (no caso daqueles em fase de estudo) ou quanto aos empreendimentos já em curso.

A antropóloga Maria Sylvia Caiuby Novaes aborda as qualidades específicas da imagem que atuam na dimensão do sensível e as distingue daquelas que propiciam o engajamento com o texto verbal.

Imagens favorecem, mais do que o texto, a introspecção, a memória, a identificação, uma mistura de pensamento e emoção. Imagens, como o próprio termo diz, envolvem, mais do que o texto descritivo, a imaginação de quem as contempla. Elementos visuais têm a capacidade de metáfora e sinestesia relação subjetiva espontânea entre uma percepção e outra que pertença ao domínio de um sentido diferente. Podemos associar algumas formas ou objetos a pessoas ou seres específicos, certos cheiros evocam a infância etc. Esta 
capacidade de metáfora e sinestesia é muito mais acentuada nas imagens quando comparadas ao texto verbal. (Novaes, 2008:463)

A antropóloga Clarice Peixoto também explica de onde vem essa capacidade de sensibilizar das imagens: "a linguagem imagética tem mais expressividade e força metafórica, tornando mais sensível à percepção dos fenômenos sociais já que é mais alusiva, mais elíptica e mais simbólica.” (Peixoto, 2014: 137)

A ideia de sensibilizar o "empreendedor" e a administração pública através de imagens, não é nova. Fernando de Tacca aborda a importância que Rondon atribuía aos registros imagéticos como "forma de convencimento" e destaca a quantidade de fotos presentes no relatório que a Comissão Rondon encaminhou ao Presidente da República, Artur Bernardes, em 1922: "são dois volumes contendo mais de quatrocentas fotografias da construção das linhas telegráficas, de aspectos de vários povos indígenas e tomadas de cenas do sertão.” (Tacca, 2002 :190). Tal forma de convencimento ou de persuasão pelas imagens conduzida por Rondon é chamada por Tacca de "estratégia de marketing":

\footnotetext{
Rondon também utilizava como estratégia de marketing vários álbuns fotográficos e os enviava na forma de relatórios aos seus superiores, como foi dito acima. Rondon tinha forte apoio dos órgãos de imprensa, nos quais sempre publicou artigos sobre seus trabalhos, e completando seu marketing apresentava os filmes feitos pelo Major Thomaz Reis em apresentações públicas, seguidas de conferências. (Idem: 191)
}

A necessidade de "sensibilizar" o empreendedor está ligada diretamente às representações vigentes no campo do licenciamento de que os engenheiros, os gerentes e os diretores, cargos de maior poder na hierarquia corporativa, por terem dificuldade em compreender as questões abordadas nos relatórios de socioeconomia, subestimariam os impactos sociais.

A importância atribuída ao audiovisual como tática no licenciamento ambiental também está ligada ao seu componente democrático. O vídeo poderia chegar a mais pessoas do que relatórios escritos por sua maior capacidade de difusão e apropriação e possibilitaria alguma interação com aqueles segmentos sociais com pouca escolaridade, denominados pelo órgão ambiental de "vulneráveis". A busca por uma linguagem menos tecnicista, mais simétrica, mais acessível, mais passível de ser compartilhada. 


\section{Obsessão inventariante e objetividade}

Na primeira metade do século XX, antropologia e cinema tinham propósitos similares: a exploração da alteridade do mundo na forma de "obsessão inventariante" com base em uma perspectiva eurocêntrica, branca, ocidental, colonialista e evolucionista. (Piault, 2002:32) E se juntaram em torno de uma compulsão: observar o outro para conhecê-lo, classificá-lo, colecioná-lo, dominá-lo. O registro visual a serviço do empreendimento colonial tinha por objetivo absorver a distância material do outro ao reduzi-lo a imagens. (Hartmann, 2002: 145)

A sanha inventariante da antropologia em busca de verdades únicas, de ideias gerais e universais ou do que havia em comum entre todos, acabou por se deparar com incontornáveis diferenças.

os momentos fugidios da experiência, as singularidades e as diferenças do Outro se fizeram transportáveis e, portanto, observáveis (...) o sonho de uma coleção concreta de feitos sociais e de formas da sociedade parecia possível. Em diversos graus, será isto que marcará as primeiras grandes empresas cinematográficas, comerciais, pedagógicas e documentais. (Piault, 2002:33)

A ideia de "imagens transportáveis e observáveis" parece apropriada à produção de imagens no licenciamento ambiental, visto que a intencionalidade primeira no uso do audiovisual em pesquisas para produção estudos de impacto ambiental era levar os argumentos de indivíduos em vias de ser ou já atingidos por grandes empreendimentos aos funcionários das empresas (não mais colonialistas como outrora, mas munidas de outras formas de "dominação, apropriação e devoração do outro") (Hartmann, 2002 :145) e, principalmente, aos técnicos do órgão ambiental, responsável por normatizar e avaliar os estudos, de modo a ajuda-los a embasar seus pareceres.

A ideia de coleção ou inventário de imagens de certa forma se aproxima da forma como fazíamos pesquisa audiovisual no licenciamento. Interessava à equipe de pesquisa filmar conversas com o máximo de pessoas de preferência em seus espaços de trabalho e moradia para poder registrar as condições dos mesmos e quando possível, mostrá-las em situações da vida cotidiana. Percorrer inúmeros lugares, repetir perguntas, buscar entender o significado de determinadas categorias pela escuta das definições dessas categorias, comparar discursos, opiniões, visões. 
A pesquisa audiovisual se estruturava de forma inventariante, não com os objetivos dos serviços coloniais, mas com a ideia de ter mais elementos para compreender as relações sociais presentes naquele território, os diversos usos e apropriações do ambiente de maneira a conseguir descobrir e justificar os impactos socioambientais sobre seus habitantes. Vale lembrar que o território a que me refiro é o que é denominado no licenciamento como área de influência; pensada, delimitada e percorrida em função do grande empreendimento e de seus possíveis usos das partes terrestre, fluvial e marítima. Partes essas que há muito já são usadas por moradores e trabalhadores desses lugares: pescadores, agricultores, sitiantes, extrativistas, vaqueiros, quebradeiras de coco, indígenas, quilombolas, caboclos etc. $\mathrm{O}$ que leva a reiterar que a área a ser percorrida é definida não a partir dos usos já existentes, mas dos interesses de uso de quem visa licenciar seu empreendimento.

A questão da objetividade associada às imagens em suporte, também ressoa na pesquisa com audiovisual no licenciamento. Afinal, nesse contexto, vídeos e fotos se tornam mais uma evidência anexada aos estudos ambientais e aos processos administrativos. Nos casos que relatei na dissertação, além dos já mencionados relatórios escritos, os documentos em questão são documentários. Também o registro audiovisual de reuniões públicas e audiências públicas são tratados como documentos, evidências de realização de atividades.

Nesse sentido, a pesquisa da antropóloga Lucybeth de Arruda acerca das coleções de fotografias do Serviço de Proteção ao Índio (SPI) merece destaque, visto que, envolve o uso de imagens em políticas públicas de relacionamento com populações indígenas. A autora aborda as especificidades da fotografia em detrimento dos documentos escritos do SPI: "via documentação escrita conseguimos apenas saber da existência dessas aldeias e suas nominações como lugares prestes a desaparecer. Através das coleções fotográficas, a aldeia se revela na prática de sua cotidianidade, engajada e encarnada de diversos agenciamentos que não estão presentes nas prestações de contas dos agentes do SPI." (Arruda, 2014: 540)

Assim como no licenciamento, as fotografias cumpririam certa função de "testemunho de que o trabalho administrativo-gerencial estava sendo realizado, e, consequentemente, servia também como atestado da 'integração' dos índios propriamente ditos (Idem, pp. 543) As imagens ganhariam mais um sentido, o de documentos comprobatórios. Além deste, tinham a função de arquivo como "registro documental 
histórico da ação do Serviço, enquanto instituição e também como política de Estado". (Idem, pp. 545)

Um caso emblemático que pude acompanhar e envolveu o uso do audiovisual tratava da comprovação da presença de pequenos barcos de pesca artesanal próximos de plataformas de petróleo com grande distância da costa. Toda plataforma possui uma zona de exclusão, área com diâmetro de 500 metros em seu entorno nas quais é proibido pescar ou transitar, a não ser que esteja a serviço da atividade de petróleo. As empresas de petróleo, diante das afirmações de pescadores artesanais de que frequentavam a área, inclusive amarrando seus barcos nas plataformas e travando relações de troca e ajuda mútua com os funcionários das plataformas, contra-argumentavam com a justificativa de que as embarcações desses pescadores não teriam estrutura para alcançar a área das plataformas, algumas há mais de 100 quilômetros da costa.

A partir de um dos processos mais interessantes de produção videográfica no licenciamento - no qual estive envolvida na somente na fase de edição de imagens comprovou-se que sim, os barcos chegavam lá. Como mencionei acima, na fase de estudos sempre trabalhávamos com equipes profissionais filmando diretamente. Esse caso específico foi uma exceção por conta da necessidade de obter imagens de pesca em alto-mar. As viagens nesses barcos de pequeno porte para alto-mar duravam dias e não comportavam a presença de uma equipe de filmagem de fora. A solução foi treinar algumas tripulações de pescadores de diferentes portos para filmarem suas viagens com pequenas câmeras digitais e manter contato com elas através de rádio comunicação para combinar a entrega do material filmado no retorno ao continente.

O resultado foi muito além do esperado em vários sentidos. Por ser um membro da tripulação por trás da câmera, os pescadores se mostravam muito à vontade. No material bruto encontramos uma situação em que comentavam o próprio processo durante a filmagem: quem afinal eram aquelas pessoas que haviam lhes confiado uma câmera, "devem ser ricos", também faziam performances para a câmera mostrando as condições precárias do local de dormir, da alimentação, faziam brincadeiras, mandavam recados. Praticamente um reality show em alto-mar. Essas imagens, como as imagens documentais em geral, nos exigiram uma postura ética clara em dar os limites de exposição daqueles pescadores na montagem final do filme.

Além do "Big Brother" da pesca, os pescadores-câmeras filmaram seus barcos entrando na zona de exclusão das plataformas, barcos amarrados a elas e a atividade de 
pesca em seu entorno. Ali estavam as "provas" de que precisávamos para confirmar o discurso dos pescadores e implicar as empresas quanto aos impactos, mas isso também desdobrava em novos dilemas. Se por um lado os pescadores corriam risco de vida por estarem atuando naquela área e poderiam levar multas da Marinha, por outro era ali que o pescado que lhes garantiria a renda estava.

Outra questão que aquelas imagens despertaram, dessa vez falo diretamente do meu engajamento com elas, foi com relação à possibilidade de manifestarem um olhar específico. Um olhar do pescador para com a sua atividade de pesca. Falo das imagens da atividade de pesca filmadas pelos pescadores. Como disse, participei apenas da fase de edição e no primeiro dia na ilha ainda não sabia exatamente como as filmagens tinham sido realizadas. A diretora do documentário quis me mostrar algumas sequências editadas que mostravam trechos de entrevistas com pescadores e imagens de "ação", ou seja, das diferentes artes de pesca se desenrolando in loco. Ao assistir aquelas imagens me impressionou a habilidade do operador da câmera ao filmar a pesca, ele parecia saber exatamente o que deveria ser filmado. Não havia hesitação naquelas imagens e mesmo com todo o balanço em alto-mar não parecia desequilibrar-se em momento algum. Surpreendida falei que aquelas imagens me passavam uma sensação de intimidade com a ação filmada e elogiei a atuação do fotógrafo profissional. Ao final, a diretora do filme revelou que aquelas imagens tinham sido feitas por um pescador e me detalhou o processo participativo de treinamento de tripulações que relatei acima.

Nos debates da $1^{a}$ Mostra do Filme Etnográfico em 1993, Vincent Carelli aborda as descobertas possibilitadas ao antropólogo pelas imagens produzidas por um "olhar específico", a partir de suas experiências no Vídeo nas Aldeias:

No material que os índios produzem fica claro que há um olhar específico, quer dizer, o sujeito está filmando o seu ritual. Ele conhece de certa maneira, apreende esse ritual. Eu mesmo como câmera, aprendi muitas tomadas que não tinha sacado antes. De repente vejo o que eles fazem e digo: não saquei essa tomada. É o olhar indígena, o índio está olhando uma coisa que ele conhece (...). Para um antropólogo é riquíssimo poder ver como é que o índio documentou o seu próprio ritual (...). Como e que o índio faz a edição na filmagem, ele faz uma decupagem no ato. E o resultado final é o resultado final. $\mathrm{O}$ antropólogo vê como ele decupou, o que ele valorizou; ele valorizou repetições, enfim descobre uma infinidade de coisas interessantíssimas. (Carelli, 1993:25) 


\section{Intencionalidade antropológica e processos de elaboração fílmica}

Marc Piault (2000) considera central investigar processos de produção até a recepção do filme pronto. São os processos de passagem da realidade à imagem e da imagem à realidade que desvendarão as motivações que levaram a produzir o filme.

A elaboração fílmica, isto é, o processo completo que vai da decisão de filmar até a apresentação do filme, passando por todas as negociações que levaram à realização, implica um desvelamento progressivo da intencionalidade antropológica. É aqui, em definitivo que se encontra o verdadeiro objeto sujeito da pesquisa (Piault, 2000 apud Hartmann, 2002: 144)

Dentro da ideia de uma intencionalidade antropológica, Piault depreende dois modos de ação/ produção audiovisual: a predação colonial caracterizada pela obsessão de inventariar e colecionar os modos de vida de outras culturas e a partir dos anos 60, uma produção distinta -alavancada pela mudança tecnológica, que possibilitou a gravação de som direto- mais descentrada, simétrica ou compartilhada, dialógica, participante. Além da passagem da realidade à imagem temos a passagem da observação à participação, que segundo Piault, só existe a partir de uma relação estabelecida e orientada teórica, ideológica e afetivamente. (Piault,2000 apud Hartmann, 2002 :180)

$\mathrm{Na}$ formulação de sua teoria antropológica da arte, Alfred Gell propôs uma abordagem da arte centrada na ação, em lugar das abordagens com ênfase na comunicação simbólica, nas definições institucionais ou nos critérios estéticos que dominaram o campo da antropologia da arte até os anos 90. Propõe superar a distinção entre arte e artefato e colocar a "agência" e a "intencionalidade" no lugar da "contemplação". Assim, uma obra de arte não seria um fim em si mesmo, não se definiria por si só, ela estaria inserida em um emaranhado de relações, presentificaria conhecimentos e um conjunto de intencionalidades cognitivas, emocionais e em vários níveis de consciência que estão direcionados para algum fim. O papel do antropólogo nessa nova antropologia da arte seria descobrir para onde essas intencionalidades apontam; como agem sobre sua "vizinhança"; quais as lógicas de ações, reações e relações sociais desencadeadas por, ou localizadas em,um determinado objeto" (Gell, 2001:185). Portanto, para Gell, todo artefato é a materialização de intencionalidades complexas de vários agentes sociais. 
Acredito que podemos encarar o audiovisual no licenciamento_ na forma de filmes que circulam e fazem parte de um contexto relaciona _como agente capaz de afetar as relações a partir de uma gama de intencionalidades daqueles que filmam e que são filmados, que causa efeitos previstos e imprevistos e por vezes consegue desestabilizar o processo social em curso.

Havia uma intencionalidade por parte da nossa equipe em consolidar o uso da ferramenta e da linguagem audiovisual no licenciamento, já que seu uso era por uma decisão metodológica da equipe de consultoria e passava pelo convencimento do financiador em relação à inovação proposta e não por uma exigência do órgão ambiental. $\mathrm{O}$ audiovisual era entendido como um instrumento de pesquisa que poderia levar vozes, visões, saberes daqueles que seriam ou já eram atingidos por grandes empreendimentos para dentro dos gabinetes dos gestores públicos e dos empresários. Além de também ser um resultado de pesquisa com linguagem mais acessível do que aquela encontrada em relatórios técnicos escritos. Em determinado momento, já não éramos mais uma equipe de antropólogas e cineastas a fazer pesquisa vídeo-documentada para elaborar Estudos de Impacto Ambiental, processo no qual detínhamos o monopólio do uso dos equipamentos, da elaboração do roteiro e da edição dos filmes. Um novo adjetivo se colocava: o participativo. E com ele o desafio de envolver os impactados em um projeto de educação ambiental para mitigação de impactos. A transição da observação à participação se deu pela elaboração e realização de oficinas de cinema ambiental como forma de diagnóstico participativo para Projetos de Educação Ambiental no contexto do licenciamento. Nessas oficinas, os participantes realizavam documentários com acompanhamento da equipe profissional, a partir de argumentos propostos por eles, sobre conflitos socioambientais existentes nas localidades, que pudessem estar relacionados aos grandes empreendimentos.

\section{Audiovisual como meio de participação/ envolvimento público}

Para Sarah Pink (2011), os métodos de antropologia visual estão avançando em um ambiente contemporâneo onde as antropologias aplicada, ativista e pública e interdisciplinar são cada vez mais centrais. Ela situa o visual aplicado à antropologia como um campo emergente de práticas inovadoras que estendem os limites da prática antropológica para criar novas e inspiradoras interfaces e que precisa ser entendido como 
desenvolvimento que faz parte da necessidade contemporânea de uma antropologia pública e inseparável da interdisciplinaridade. (Pink, 2011:437)

Pink usa a categoria antropologia visual participativa para abarcar uma gama de abordagens, métodos e projetos que procuram usar métodos visuais e mídia para criar meios através das quais grupos específicos de pessoas, cujas vozes talvez não sejam ouvidas com tanta frequência em domínios públicos, podem expressar suas experiências e seus sentimentos. E afirma que esse trabalho cria uma forma de antropologia pública através da qual o conhecimento compartilhado entre antropólogo e participantes é expressa, ou através da qual os antropólogos facilitam a representação das experiências e conhecimentos dos participantes. (Pink, 2011:447)

Nesses percursos na consultoria ambiental, ambientalização, desenvolvimento e audiovisual estavam imbricados na questão da participação popular ou do envolvimento público ${ }^{6}$ no licenciamento ambiental. Dentro da tática de legitimação do audiovisual como meio e expressão nos diagnósticos do licenciamento, a metodologia também deveria contemplar a exigência/requisito de ser "participativa". Para atender aos requisitos do IBAMA, fez-se uma interpretação do "participativo" como: autoria/ participação ativa de moradores de municípios impactados na roteirização, filmagem e edição de vídeos documentários de curta-metragem sobre conflitos socioambientais relacionados aos impactos de grandes empreendimentos.

A realização de diagnósticos socioambientais participativos para Projetos de Educação Ambiental do licenciamento inaugurou outra fase de nosso trabalho em consultoria ambiental. $\mathrm{O}$ uso do audiovisual como tática para diminuição de assimetrias no jogo do licenciamento também vinha de uma crença nessa linguagem como mobilizadora, como atrativa, como agente ativador da "participação".

A metodologia resultava de um cruzamento de referências: métodos de produção audiovisual, a linguagem de documentário e alguns princípios da pesquisa antropológica como: estranhar o familiar e naturalizar o estranho num exercício primeiro de alteridade, conhecer as diferentes versões e pontos de vista acerca de uma determinada questão,

\footnotetext{
${ }^{6} \mathrm{O}$ envolvimento ou participação popular na gestão pública pode ser definido como: "uma forma efetiva de comunicação social entre o governo e outros agentes sociais numa dada sociedade (...) Esse envolvimento público pode se fazer de forma fraca ou forte, dependendo do contexto institucional mais amplo e da natureza e do grau da transparência, bem como da abertura dos processos de interação e comunicação entre governos e cidadãos". (Leite Lopes, 2004 :115)
} 
identificar conflitos ambientais e agentes sociais envolvidos neles, estabelecer recortes, valorizar o saber do outro, pensar a relação com o território. A antropologia compartilhada, também chamada de dialógica ou antropologia simétrica desenvolvida pelo cineastaantropólogo Jean Rouch; - a educação pela experiência proposta pelo centro de formação para realização de documentário Ateliers Varan criado por Jean Rouch em 1981; - as práticas não formais de educação popular, pesquisa-ação e pesquisa participante; - a ideia de diagnóstico como parte de um processo mais amplo de intervenção social e não apenas como resultado de uma pesquisa.

Uma oficina que envolvesse produção audiovisual poderia atrair tanto as pessoas interessadas nas questões socioambientais como em cinema, comunicação, artes. Como de fato atraiu. As oficinas aconteciam naqueles municípios que estivessem na "área de influência" do empreendimento. De modo geral, conseguíamos atingir um público com perfil variado: estudantes de Ensino Médio da rede pública, universitários, funcionários públicos como fiscais ambientais e professores de escola, membros de ONGs, filhos de pescadores, moradores de favelas e de localidades rurais, que acabavam por atuar como “intermediários" para alcançarmos os "sujeitos prioritários da ação educativa", aqueles mais "vulneráveis" (DAE/CGPEG/IBAMA, 2010) em relação aos impactos socioambientais, como pescadores artesanais, agricultores familiares, ribeirinhos, ambulantes, migrantes pobres, extrativistas, quilombolas, moradores de favelas entre outros.

Ao possibilitarmos aos alunos das oficinas condições de produzirem documentários sobre os conflitos socioambientais locais, estávamos criando uma tática de aproximação com aqueles sujeitos entendidos como vulneráveis, de mais difícil mobilização que acabavam por se tornar personagens dos filmes. Em todas as turmas formadas em oficinas havia pessoas com maior e menor grau de vínculo com esses sujeitos e de inserção nas localidades em que viviam. O processo de oficina deslocava o consentimento necessário para produzir um filme para alguém "próximo", alguém do lugar, que saberia aonde ir, com quem falar, facilitando as negociações junto aos personagens.

A produção videográfica (30 documentários) desse projeto contribuiu para que ocorresse uma parceria inédita do Ministério do Meio Ambiente (MMA) com a Secretaria do Audiovisual (SAV). Tal parceria resultou na implantação do Circuito Tela Verde ${ }^{7}$,

${ }^{7}$ Circuito tela verde (mma.gov.br) 
projeto de distribuição de dvds de "vídeos ambientais" para associações, escolas, sindicatos e outros tipos de organizações não governamentais que fossem consideradas Salas Verdes. Como contrapartida, essas organizações deveriam produzir mostras para exibição dos vídeos para os moradores dos municípios.

O Circuito tem como objetivo promover a sensibilização e reflexão dos públicos sobre o meio em que vivem; levar filmes sobre a temática a setores excluídos dos circuitos dos festivais de vídeos ambientais, produções premiadas e/ou de reconhecida importância para conscientização socioambiental; e estimular a produção de materiais pelas próprias comunidades (...). Dessa forma, busca-se conscientizar as pessoas da importância de suas ações nos processos de gestão ambiental. (texto do blog do Circuito Tela Verde)

A grande novidade na política federal foi introduzir conteúdos audiovisuais como instrumentos de educação ambiental para gestão em escala nacional. A política ainda se encontra em atividade e hoje, conta com grande acervo de filmes produzidos por pontos de cultura, produtoras, ONGs e coletivos comunitários, o que demonstra maior acessibilidade aos meios de produção audiovisual digital ao longo dos anos.

Outro efeito da introdução do audiovisual no licenciamento ambiental federal foi o lançamento de normas para divulgação dos programas de educação ambiental e demais projetos ambientais condicionantes do licenciamento por parte do órgão ambiental federal. A normatização ocorreu somente em 2010, antes disso nossa equipe consultou a equipe do IBAMA sobre como divulgar sua logomarca e contextualizar os vídeos ao processo de licenciamento. Dessa consulta informal veio uma orientação de que a logomarca do IBAMA deveria constar em todos os filmes e materiais gráficos relacionados, bem como um texto na abertura de cada vídeo informando que aquele vídeo era "produto do projeto de educação exigido pelo IBAMA como medida compensatória do licenciamento ambiental do empreendimento (nome do empreendimento)" (DAE/ CGPEG/IBAMA, 2010).

Na Nota Técnica lançada em 2010 a justificativa para normatizar a divulgação dos projetos ambientais condicionantes do licenciamento é deixar claro para o público que a execução dos projetos se baseia em uma exigência legal e não no voluntarismo consciente das empresas. Principalmente em projetos de educação ambiental, essa informação é importante para "evitar que o público participante confunda as ações executadas como 
sendo resultado de projetos de responsabilidade social das empresas" (DAE/ CGPEG/IBAMA, 2010). Projetos de responsabilidade social são investimentos voluntários da empresa, já o financiamento de projetos de mitigação e compensação é uma obrigação legal decorrente do licenciamento de determinado empreendimento. Com relação à inserção de logomarcas, o IBAMA permite que a empresa divulgue a própria logomarca desde que obedeça a seguinte padronização: “(i) A logomarca da empresa deverá estar acompanhada do nome do empreendimento licenciado. (ii) A logomarca da empresa deverá ser proporcional ao tamanho da logomarca do IBAMA.” (Idem)

A Educação Ambiental para gestão preconizada no licenciamento busca o fortalecimento da democracia pela via das metodologias participativas - objetivo louvável, mas de difícil realização. A participação não é uma fábula, pois existe, mas não na forma ideal colocada nas normas técnicas. Na Bacia de Campos, região petrolífera que abrangia 10 municípios litorâneos do estado do Rio de Janeiro, executamos durante alguns anos um projeto de educação ambiental e com a continuidade pudemos observar que nosso maior problema era conseguir garantir a participação de um mesmo grupo de pessoas em atividades regulares de formação para gestão ambiental. Manter 10 grupos "mobilizados" para uma proposta a princípio voluntária. Manter a estabilidade das relações entre os participantes que estavam formando um grupo não por afinidades anteriores, mas por uma necessidade colocada pelo licenciamento. Ao mesmo tempo em que nos deparávamos com a dificuldade da participação contínua, começamos a perceber que, diferente das experiências de laboratório, as experiências em educação não formal não tinham resultados passíveis de controle ou mensuração.

Lidávamos com inúmeros fatores relacionados aos pertencimentos e projetos de vida dos participantes, além de trabalharmos com um público absolutamente diversificado em termos de idade, inserção política, vinculação religiosa, escolaridade e classe social. A participação social tem uma série de limites, principalmente porque os sujeitos em situação de maior vulnerabilidade socioambiental, impactados pela atividade em licenciamento, que são justamente os prioritários nesse processo, são os que têm mais dificuldade em participar. Como viabilizar um processo educativo complexo, longo e que demanda muito tempo de pessoas que vivem em situação de precariedade extrema, empobrecidas, em subempregos, com trabalhos informais, que estão a reboque de uma urbanização acelerada ou com um cotidiano regido pelos ciclos naturais como pescadores e agricultores em cenário de crise ambiental? 
“Aprender a ver e saber pensar e fazer pensar em imagens" é o outro desafio em processos descontínuos, regidos por contratos curtos vigentes no mercado de consultoria. Audiovisual encarece os projetos, demanda equipamentos, manutenção e a quem interessa, transformar populações impactadas em observadores dos impactos, criadores de produtos midiáticos, capazes de abduzir a agência, capazes de ser instrumento de intencionalidades complexas? Quem quer ter seus impactos divulgados? Ser controlado pela gestão participativa, pelo mídia-ativismo? Certamente que não os empreendedores.

Quem tem poder de regular a indústria e seus impactos? A "população parceira" se quiser fazer uma denúncia ambiental contra a indústria vai recorrer a quem? Como se blindar de ameaças e não correr riscos pela exposição? Por fim, a norma do licenciamento diz que quem deve fornecer os meios para "a produção e aquisição de conhecimentos e habilidades e contribuir para o desenvolvimento de atitudes, visando a participação individual e coletiva na gestão do uso sustentável e na conservação dos recursos ambientais, bem como, na concepção e aplicação de decisões que afetam a qualidade ambiental (meios físico natural e sociocultural)" são as empresas que operam os grandes empreendimentos licenciados. (CGEAM/IBAMA:2002)

Pode o empreendedor agenciar essa produção em seu favor com a justificativa de uma entrada mais "participativa", mais "responsável e isso reverter em marketing para a aceitação da empresa e do empreendimento entre os impactados e as lideranças? O uso do audiovisual alimentaria o paradigma da adequação, do consenso no licenciamento, atuando como um domesticador dos conflitos? Há um conjunto de fatores que incidem sobre essas questões: o entendimento da equipe do órgão ambiental sobre o uso do audiovisual no licenciamento e sua autoridade diante das empresas; a postura do empreendedor e da empresa de consultoria e a capacidade de pressão e participação dos grupos impactados.

\section{Desenvolvimento, mercado e antropologia pública: entre o campo minado e a experimentação}

Nesse jogo temos distorções, pois o "cliente" da empresa de consultoria é o empreendedor, com quem lidamos muito mais de perto do que com o órgão ambiental. $\mathrm{O}$ consultor como contratado do empreendedor não pode fazer reuniões técnicas a sós com o órgão ambiental, a não ser que o empreendedor autorize, mesmo assim dificilmente 
uma consultoria vai propor algo do gênero, simplesmente não é colocado em questão. Outra "anedota" trágica da consultoria é que a emissão da licença ambiental é motivo de alegria para a empresa de consultoria, pois isso quer dizer que o cliente está satisfeito, e há possibilidade de continuidade do trabalho para os consultores. Distorção causada pela relação de mercado, visto que o que deveria ser comemorado é um trabalho técnico de qualidade que garantisse uma avaliação embasada do IBAMA e que poderia resultar na emissão ou não da licença.

Sob julgamento constante, o consultor é acusado por parte da academia de elaborar "relatórios tendenciosos", de "negociar os direitos" dos impactados, de "forçar consensos" devido à relação de clientela à qual se submete por estruturas que conformam o mercado de trabalho em que está inserido. Por outro lado, o consultor também é acusado pelo empreendedor de estar a favor dos grupos impactados, superdimensionar impactos, “inventando problema onde não existe”. Até incriminações relacionadas à filiação política de consultores acontecem. Finalmente, o consultor tem seu trabalho técnico avaliado pelo órgão ambiental e às vezes é cobrado para resolver o insolúvel, como, por exemplo, produzir indicadores de resultados em projetos cujo orçamento não condiz com a dimensão do que precisa ser feito, porque nem o órgão ambiental nem a consultoria têm de fato ingerência sobre os orçamentos do empreendedor.

Ao que parece não há escapatória ou saída visível do labirinto, resta “comer pelas beiradas". Esse sentimento de limitação e inevitabilidade estaria relacionado ao fato de estarmos envolvidos em projetos de desenvolvimento que envolvem interesses transnacionais e enorme quantidade de capital, "processos de extrema complexidade sobre os quais não temos nenhum controle quanto ao andamento e o desfecho. (...) Assim, no trabalho de consultoria estamos pisando num campo minado repleto de contradições e ambiguidades" (Baines, 2004:31).

Os projetos para mitigação e compensação de impactos, como por exemplo projetos de educação ambiental, tem uma carga bastante experimental, são metodologias em teste, envolvem uma diversidade de pessoas de diferentes perfis e se misturam a processos permeados por conflitos de toda ordem. Aliás, o sistema de licenciamento em si é uma grande experimentação em processo, mas, por seu caráter normativo, essa dimensão de que tudo está em construção fica escamoteada.

Cabe também ressaltar que boa parte dos profissionais de consultoria que fazem parte de minha rede de relações_cientistas sociais, historiadores, biólogos, ecólogos, 
engenheiros florestais, geógrafos_ preferia estar a serviço não do licenciamento de grandes projetos de energia de corporações mas de projetos de recuperação de áreas degradadas, de projetos de educação ambiental crítica e emancipatória, de processos de agroecologia, da assessoria a gestão participativa de reservas extrativistas, da recuperação de mananciais, reciclagem, desenvolvimento de matrizes energéticas menos predatórias, da demarcação de terras indígenas e quilombolas, implantação de assentamentos de reforma agrária, turismo comunitário, geração de rende com economia solidária, valorização cultural e registro de conhecimentos tradicionais. Em suma, estar a serviço da construção de outro modelo de desenvolvimento que não este baseado em grandes empreendimentos industriais poluidores.

No entanto, mesmo repleto de distorções e fragilidades o licenciamento ambiental ainda é uma exigência legal que visa regular os empreendimentos poluidores (sob ameaça de desmonte por projeto de lei voltado para sua flexibilização) e possibilita a uma gama imensa de profissionais realizar pesquisa aplicada em suas áreas de saber, o que é cada vez mais raro em nosso país.

De 2016 a 2021, passamos por um golpe parlamentar e por alguns desastres como o rompimento de barragens de mineração em Brumadinho (MG) e Mariana (MG) por descaso das empresas responsáveis sem responsabilização efetiva pelos danos, por vezes irreversíveis. Tais acontecimentos abalaram todos os paradigmas de "gestão de riscos" que dominam os projetos de engenharia dos grandes empreendimentos. Além disso, desde 2019, vivemos sob um governo de extrema-direita que vem pressionando para o desmonte do sistema público de licenciamento ambiental e dos espaços de participação social, que já são poucos e precários.

Para Eriksen (2014), a Antropologia Pública consiste em uma tentativa de preencher a lacuna e superar a alienação entre a comunidade antropológica como um grupo profissional fechado e a sociedade global que a antropologia estuda e da qual os antropólogos fazem parte (Eriksen, 2014). Na visão de Martijn de Koning (2009), "existem dois princípios fundamentais da antropologia pública (que também a distingue da antropologia aplicada): 1. Responsabilidade pública, 2. Tentar compreender as estruturas que enquadram e restringem as soluções para os problemas” (De Koning, 2009 apud Erilksen, 2014).

O primeiro critério enfatiza a disseminação do conhecimento e o compromisso de participar de um amplo intercâmbio de ideias que não seja limitado pela disciplina 
acadêmica de antropologia (nem mesmo pela academia); o outro critério compromete a antropologia pública a lidar com questões que envolvem as populações locais, presumivelmente enquadrando-as de novas maneiras. (Eriksen, 2014)

Na dissertação de mestrado (2015) me perguntava se a antropologia praticada no licenciamento ambiental "seria uma antropologia de mercado, uma antropologia fast-food, para consumo rápido, que não é feita com os melhores ingredientes, mas talvez ainda guarde algum sabor?” (Pitanga, 2015:84).

Hoje, em 2021, vislumbro um lugar na Antropologia Pública para as experiências que abordei. Afinal, os cientistas sociais atuam como consultores por exigência da legislação ambiental federal, a partir dos termos de referência de órgãos ambientais e intervenientes públicos e temos nossa produção avaliada por eles. Não só por isso. Aqui o sentido de uma antropologia pública também diz respeito a alcançar públicos mais amplos, a compartilhar produção e autoria e a estimular a participação social pela produção de imagens e sons por aqueles que serão atingidos por empreendimentos de grandes empresas, bem como fazer suas visões e opiniões chegarem a outras instâncias.

\section{REFERÊNCIAS}

ACSELRAD, Henri. Ambientalização das lutas sociais - o caso do movimento por justiça ambiental. Estudos Avançados, São Paulo, v. 23, n. 68, 2010.

ARRUDA, Lucybeth C. de. "Como atuar e viver nos postos do SPI: reflexões a partir de três coleções etnográficas da seção de estudos" In: MENDONÇA, João Martinho de; FERRAZ, Ana Lúcia Camargo. (Org.). Antropologia Visual: perspectivas de ensino e pesquisa. 1a ed. Brasília: ABA Publicações, 2014.

BAINES, Stephen G. Antropologia do desenvolvimento e a questão das sociedades indígenas. Revista Anthropológicas, ano 8, v. 15, n. 2, 2004.

BISPO, Antonio. Colonização, quilombos: modos e significações. Editora da UNB, Brasília, 2015. 
BONETTI, Alinne. A ONG e a antropóloga - Da experiência etnográfica à experiência profissional. Revista Humanas. Cidadania, Democracia e Políticas Públicas. V. 26/27, $n^{\circ} 1 / 2$. Porto Alegre, IFCH/UFRGS, 2004/2005.

BRONZ, D. Empreendimentos e empreendedores: formas de gestão, classificações e conflitos a partir do licenciamento ambiental, Brasil, século XXI. Tese de Doutorado, Museu nacional/UFRJ, 2011.

CARNEIRO, M. J.; MEDEIROS, C. P.; LAURENT, C. Usos das ciências na regulação ambiental: diálogos entre saberes e políticas públicas. Anais da $26^{a}$. Reunião Brasileira de Antropologia, Porto Seguro, 2008.

CERTEAU, M. de A invenção do cotidiano. Petrópolis, RJ: Vozes, 2007.

CGEAM/CGPEG/IBAMA. Orientações Pedagógicas do IBAMA para a elaboração e implementação de Programas de Educação Ambiental no licenciamento de atividades de produção e escoamento de petróleo e gás natural. Brasília: IBAMA, 2005 (mimeo).

ERIKSEN, Thomas H. "Public Anthropology”. In Russell Bernard and Clarence Gravlee (eds.), Handbook of Methods in Cultural Anthropology. Thousand Oakds: Rowman \& Littlefield Publishers, pp. 719-734, 2014.

GALLOIS, Dominique e CARELLI, Vincent. “Seminário Cinema e Povos Indígenas” In: MONTE-MOR, Patrícia e José Inácio, Parente org. Cinema e Antropologia - Horizontes e Caminhos da Antropologia Visual. Interior Produções, RJ. 1994.

GELL, Alfred. "A rede de Vogel, armadilhas como obras de arte e obras de arte como armadilhas. In Arte e Ensaios - Revista do Programa de Pós- Graduação em Artes Visuais. Escola de Belas Artes. UFRJ. Ano VIII - número 8: 174-191, 2001.

GOLDMAN, Marcio. Alteridade e experiência: antropologia e teoria etnográfica. Revista Etnográfica v.10 n.1 Lisboa maio, 2006. pp 161-173. 
HARTMANN, Luciana. Resenha: PIAULT, Marc-Henri. Anthropologie et cinema. Paris: Nathan, 2000, p. 284. Revista 1LHA - Florianópolis, v.4, n.1, julho de 2002.

LEITE LOPES, J. S. (Coord.); ANTONAZ, Diana; PRADO, Rosane, SILVA, Gláucia (Org.). A ambientalização dos conflitos sociais: participação e controle público da poluição industrial. Rio de Janeiro: Relume Dumará, 2004.

MAZUREC, B. Reconhecimento Étnico Quilombola no Licenciamento Ambiental. Dissertação de Mestrado. CPDA/UFRRJ. 2012.

NOVAES, Sylvia Caiuby. Imagem, magia e imaginação: desafios ao texto antropológico. Revista Mana, Museu Nacional/UFRJ Rio de Janeiro, v. 14, n. 2, outubro de 2008.

PACHECO DE OLIVEIRA, J. Etnografia enquanto compartilhamento e comunicação: desafios atuais às representações coloniais da antropologia. In: FELDMAN-BIANCO, Bela (org.). Desafios da Antropologia Brasileira. Brasília: ABA, 2013.

PEIXOTO, Clarice E. “Antropologia visual: como transmitir esse conhecimento" In: MENDONÇA, João Martinho de; FERRAZ, Ana Lúcia Camargo. (Org.). Antropologia Visual: perspectivas de ensino e pesquisa. 1a ed, v. 1. Brasília: ABA Publicações, 2014.

PIAULT, Marc-Henri. Antropologia y cine. Madrid, Espanha. Cátedra Signo e Imagem, 2002.

PINK, Sarah. Images, Senses and Applications: Engaging Visual Anthropology, Visual Anthropology, 24:5, 437-454, 2011.

ROVERE, Emilio Lebre La. Requisitos para inserção da dimensão ambiental no planejamento do setor elétrico. In: Estado, energia elétrica e meio ambiente. Rio de Janeiro: UFRJ/Coppe/ PPGAS, 1995.

SCHUCH, Patrice. O estrangeiro em "campo": atritos e deslocamentos no trabalho antropológico. Revista Antropolítica, Niterói, v. 12/13, n. 1/2 sem/2003. 
SOARES, Barbara M. No executivo: limites e perspectivas. In: CORREA, Mariza (org.) Gênero e Cidadania. Campinas: Unicamp/PAGU, 2002.

TACCA, Fernando de. Rituaes e festas Bororo. A construção da imagem do índio como 'selvagem’ na Comissão Rondon. Revista de Antropologia, São Paulo, USP, V. 45 no 1. 2002.

TORRESAN, Ângela. A pedagogia de ensino do centro granada de Antropologia Visual: notas para um exercício comparativo In: MENDONÇA, João Martinho de; FERRAZ, Ana Lúcia Camargo. (Org.). Antropologia Visual: perspectivas de ensino e pesquisa. 1a edição. Brasilia: ABA Publicações, 2014.

VERSIANI, Daniela B. Autoetnografias: conceitos alternativos em construção. Rio de Janeiro, 7 Letras, 2005.

ZHOURI, Andréa. Conflitos entre Desenvolvimento e Meio Ambiente no Brasil: Desafios para a antropologia e os antropólogos. In: FELDMAN-BIANCO, Bela (org.). Desafios da Antropologia Brasileira. Brasília: ABA, 2013.

Recebido: 20/12/2020

Aprovado: 01/03/2021 